\title{
Üniversiteli Sporcu Öğrencilerin Beslenme Destek Ürünleri Kullanım Durumu
}

\author{
Serap ANDAÇ ÖZTÜRK ${ }^{1}$, İndrani KALKAN ${ }^{1}$, Ceyda DURMAZ ${ }^{1}$, \\ Merve PEHLIVAN ${ }^{2}$, Gökçen ÖZÜPEK ${ }^{1}$, Zeynep Damla BAKMAZ ${ }^{1}$
}

\begin{abstract}
Öz
Amaç: Sporcular yüksek performansa ulaşmak amacı ile baskı altındadırlar, bu nedenle performanslarını maksimize edebileceğine ve müsabakalarda kendilerine yardımcı olabileceğine inandıkları için besin takviyesi kullanımına yönelmektedirler. Bu çalışma İstanbul Aydın Üniversitesi öğrencisi olan profesyonel sporcuların beslenme alışkanlıkları ve besin takviyesi kullanım oranlarının araştırılması amacıyla yürütülmüştür.
\end{abstract}

Gereç ve Yöntem: Bu çalışma 2017-2018 akademik yılında çeşitli branşlarda oynayan 23 erkek, 22 kadın olmak üzere toplam 45 sporcu üzerinde yürütülmüştür. Sporculara mevcut literatür göz önüne alınarak araştırmacılar tarafından geliştirilen demografik özellikler, besin destek ürünü kullanımı ile ilgili sorulardan oluşan anket uygulanmıştır.

Bulgular: Mevcut çalışmada sporcuların; \%55.6'sının günde 3 ana öğün, \%44.4'ünün günde 2 ara öğün yaptığı görülmektedir. Sporcuların \%82.2'sinin öğün atladıkları tespit edilmiştir. Öğle yemeği \%44.4 ile en çok atlanılan öğün olup, \%30.6 ile kahvaltı öğünü bunu takip etmektedir. Ara öğün tercihi olarak kahve ve çikolata tüketiminin çok daha fazla olduğu meyve ve kuruyemiş tercihinin ise düşük olduğu görülmektedir. Sporcuların \%71.1'inin besin destek ürünü kullanmadığı, \%28.9'unun ise besin destek ürünü kullandığı görülmektedir. En fazla kullanılan besin destek ürünleri aminoasit, karbonhidrat barları, sporcu içeceği, kreatin, kafein, vitamin ve kilo aldırıcı tozlardır. Genel olarak sporcuların \%30.8'i güçlü olmak, \%30.8'i ise performanslarını arttırmak için besin destek ürünlerinin kullanmaktadır.

Sonuç: Neredeyse tüm sporcular spor kariyerlerinin bir döneminde besin takviyesi kullanmaktadır ve takviye kullanımı genellikle antrenör tarafından şekillendirilmektedir. Genç sporculara performans artışı için dengeli bir beslenme programının yeterli olduğu eğitimlerle ve uygulamalarla aktarılarak, gereksiz besin destek ürünü kullanımının önüne geçilmesi yararlı olacaktır.

Anahtar Kelimeler: Sporcu, Besin destek ürünü, Beslenme

\footnotetext{
${ }^{1}$ İstanbul Aydın Üniversitesi Sağlık Bilimleri Fakültesi Beslenme ve Diyetetik Bölümü, Küçükçekmece, İstanbul, Türkiye.

${ }^{2}$ Medipol Üniversitesi Sağlık Bilimleri Fakültesi Beslenme ve Diyetetik Bölümü, Beykoz, İstanbul, Türkiye. Yazışma adresi: Dr. Serap ANDAÇ ÖZTÜRK İstanbul Aydın Üniversitesi Sağlık Bilimleri Fakültesi Beslenme ve Diyetetik Bölümü, Beşyol Mah. İnönü Cad. No:38 Küçükçekmece, İstanbul, Türkiye. Tel: 4441428 E-mail: serapozturk@aydin.edu.tr ORCID ID: 0000-0002-6253-4118. Geliş tarihi: 5 Ocak 2020 Kabul tarihi: 13 Mart 2020
}

Doi num: 10.17932/IAU.TFK.2018.008/2020.301/tfk_v03i1002 


\title{
Usage of Nutritional Supplements among University Student Athletes
}

\begin{abstract}
Objective: Athletes are constantly under pressure to achieve high performance and turn to dietary supplements as they believe that these products can maximize their competitive performances. This research was conducted on student athletes of Istanbul Aydın University in order to study the nutrition and supplement usage habits of the participants.

Material and Methods: This study was conducted in 2017-2018 academic year on participants using a questionnaire developed by the researchers, according to the literature. A total of 45 individuals, 23 were males and 22 females, from various branches, participated in this study.

Results: Of the participants, $55.6 \%$ consumed three, while $44.4 \%$ consumed two main meals daily. Obtained results suggested that $82.2 \%$ of participants skipped meals. Lunch was among the most skipped meal (44.4\%) followed by breakfast (30.6\%). Coffee and chocolate were the most preferred snacks whereas fruits and nuts were least preferred. It was determined that $28.9 \%$ of the athletes used nutritional supplements and $71.1 \%$ did not. The most commonly used nutritional supplements are amino acids, carbohydrate bars, sports drink, creatine, caffeine, vitamins and weight-gaining formula powders. Regarding motives behind supplement usage, $30.8 \%$ used for gaining physical strength and $30.8 \%$ for improving performance.

Conclusion: Majority of athletes used dietary supplements during particular phases of their sports careers, usage were mostly planned by their coach. It may be recommended that knowledge regarding the sufficiency of a balanced nutrition for improvement of sports and performance must be stressed upon young athletes through theoritical and practical trainings thus preventing unnecessary usage of dietary supplements which have adverse effects on health.
\end{abstract}

Keywords: Athletes, Dietary supplements, Nutrition

\section{Giriş}

Sporcular, yüksek performansa ulaşma hedefleri yüzünden kendilerini baskı altında hissetmektedirler. $\mathrm{Bu}$ nedenle, performanslarını maksimize edebileceği ve müsabakalarda kendilerine yardımcı olabileceği inancı ile besin takviyesi kullanımına yönelmektedirler (1). Doğru beslenme bilgisi ve yeterli besin öğesi alımının atletik performansı arttırmakta anahtar bileşenlerden biri olduğu kabul edilmektedir (2). Çok sayıda sporcu, besin destek ürünlerini bu maksatla kullanmaktadır $(3,4)$.

Literatürdeki çalışmalar incelendiğinde sporcuların genel olarak sağlıklı kalabilmek, enerjiyi arttırabilmek, immün sistemi desteklemek, atletik performans, dayanıklılığın arttırılması, yüksek antrenman yükü ile baş edebilme, toparlanmayı maksimize edebilme gibi gerekçelerden dolayı besin destek ürünü kullandıkları ya da kullanmanın gerekli olduğunu düşündükleri saptanmıştır $(1,5,6)$.

Besin destek ürünleri ticari olarak mevcut olan ve normal diyete ek olarak tüketilen ya da diyeti desteklemesi beklenen vitamin, mineral, bitkisel ekstrakt, amino asit ya da diğer besin bileşenlerini ihtiva eden ürünler olarak tanımlanmaktadır $(2,6)$. Besin destek ürünleri endüstrisi dünyada en hizlı büyüyen pazarlardan bir tanesidir (7). Sporcular arasında besin destek ürünü kullanımı periyodik olarak çalışılmıștır, buna göre ilerleyen zaman içinde sporcuların bu ürünleri kullanımlarının giderek $\operatorname{arttığ~}_{1}$ raporlanmıştır (5). Yapılan çalışmalarda, sporcular arasında besin takviyesi kullanım oranının \%32-99 olduğu ve prevalansın yaş, cinsiyet, spor branşı, sezon ve coğrafyaya göre değişmekte olduğu bildirilmektedir (2,7-9).

Petroczi ve ark. yaptıkları çalışmada, genç sporcuların \%78'inin, besin destek ürünü kullanımının sportif başarı için vazgeçilmez olmadığını düşünmelerine rağmen bu sporcuların $\% 48$ 'inin besin destek ürünü kullandığını bildirmektedir (1). Başka bir çalışmada ise futbolcuların $\% 50$ 'den fazlasinın protein takviyesinin kas gelişimi ve büyümesi için gerekli olduğuna inandıkları saptanmıştır (4). 
Fiziksel performans ve ağrıya toleransı arttırmak için kullanılan ergojenik yardım ürünleri arasında en popüler olanları sporcu içecekleri, mineraller, kafein koenzim Q10 ve karnitindir (4). Sporcu performansını artırmak için birçok ürün olmasına rağmen çok azının güvenliliği ve etkinliği kanıtlanmıştır (7). Besin destek ürünleri kullanım tercihlerini etkileyen davranışsal faktörlerin anlaşılması, takviyelerin yararları ve riskleri hakkında sporcuların bilgilendirilmesi ve eğitimi çok önemlidir (4). Besin destek ürünleri ile ilgili medya kanallarında birçok bilgi yer almaktadır fakat bu bilgiler genel olarak kafa karıştırıcı ve çelişkilidir (9).

Bu çalışmanın amacı, üniversitemizdeki profesyonel sporcuların beslenme alışkanlıklarını tespit etmek, besin destek ürünü kullanım durumlarını, varsa kullanılan ürünlerin neler olduğunu belirlemek, kullanım amaçlarını ve besin takviyesi kullanımına yönlendiren kaynağın neler olduğunu araştırmaktır.

\section{Gereç ve Yöntem}

Bu çalışma 2017-2018 yılları arasında İstanbul Aydın Üniversitesi öğrencisi olan ve çeşitli spor dallarında profesyonel (milli ya da liglerde oynayan) olarak oynayan toplam 45 sporcunun katılımıyla yapılmıştır. Çalışma için etik onay, İstanbul Aydın
Üniversitesi etik kurulundan 08.03.2017 tarih ve 2017/05 sayılı karar ile alınmıştır. Katılımcılara literatür doğrultusunda araştırmacılar tarafindan geliştirilen anket uygulanmıştır. Anket kapsamında sporcuların demografik bilgileri (yaş, cinsiyet, hangi sporla uğraştığı), besin takviyesi kullanım durumu, besin takviyesini kimlerin önerdiği sorgulanmıştır. Çalışmada elde edilen verileri değerlendirmek için SPSS PASW 18' istatistik paket programı kullanılmıştır. Verilerin değerlendirilmesinde ayrıca tanımlayıcı istatistikler kullanılmıştır. Tanımlayıcı istatistik değerlendirmeler için nitel verilerde say1 (S) ve yüzde (\%) değerler hesaplanmıştır.

\section{Bulgular}

Çalışmaya katılan sporcuların \%51.1'i erkek, \%48.9'u kadındır. Sporcuların genel özelliklerine ilişkin bilgiler Tablo 1'de sunulmaktadır. Katılımcıların ilgilendikleri spor dallarına göre \%51.1'inin diğer seçenekleri arasında yer alan (karate, güreş, muay thai, kung fu, hentball, hanball) branşlarda, \%13.3'ünün ise voleybol branşında yer aldığı görülmektedir. Sporculara beslenmeye ayırmış olduğunuz aylık bütçe ne kadardır diye sorulduğunda, \%11.1'i $100 \mathrm{TL}$ altında, \%62.2'si 100-500 TL arasında, \%20'si 500-1000 TL arasında, $\% 6.7$ ' si ise 1000 TL ve üzerinde bütçe ayırdıklarını belirtmiştir. 
Tablo 1. Sporcuların genel özelliklerine ilişkin bilgiler

\begin{tabular}{|c|c|c|}
\hline & $\mathbf{S}$ & $\%$ \\
\hline \multicolumn{3}{|l|}{ Cinsiyet } \\
\hline Erkek & 23 & 51.1 \\
\hline Kadın & 22 & 48.9 \\
\hline \multicolumn{3}{|l|}{ İlgilenilen spor dalı } \\
\hline Basketbol & 3 & 6.7 \\
\hline Voleybol & 6 & 13.3 \\
\hline Futbol & 4 & 8.9 \\
\hline Tenis & 2 & 4.4 \\
\hline Yüzme & 2 & 4.4 \\
\hline Koşu & 1 & 2.2 \\
\hline Fitness & 2 & 4.4 \\
\hline Boks & 2 & 4.4 \\
\hline Diğer (karate, güreş, muay thai, kung fu, hentball, hanball) & 23 & 51.1 \\
\hline \multicolumn{3}{|l|}{ Beslenmeye harcadığınız para } \\
\hline$\leq 100 \mathrm{TL}$ & 5 & 11.1 \\
\hline $100-500 \mathrm{TL}$ & 28 & 62.2 \\
\hline $500-1000 \mathrm{TL}$ & 9 & 20.0 \\
\hline$>1000 \mathrm{TL}$ & 3 & 6.7 \\
\hline
\end{tabular}

Sporcuların beslenme alışkanlıkları incelendiğinde, \%55.6'sının günde 3 ana öğün, \%44.4'ünün günde 2 ara öğün yaptığı görülmektedir. Bireylerin \%82.2'si öğün atlarken, \%44.4'ünün öğlen öğününü atladıkları, \%30.6’sının ise en çok kahvaltı öğününü atladıkları görülmektedir (Tablo 2).

Tablo 2. Sporcuların beslenme alışkanlıklarına ilişkin veriler

\begin{tabular}{lcc}
\hline & S & $\%$ \\
\hline Kaç ana öğün yaparsınız? & 16 & 35.6 \\
\hline 2 öğün & 25 & 55.6 \\
3 öğün & 4 & 8.9 \\
4 ve daha fazla & 18 & 40.0 \\
\hline Kaç ara öğün yaparsınız? & 44.4 \\
\hline 1 öğün & 20 & 15.6 \\
2 öğün & 7 & 82.2 \\
3 öğün & & 17.8 \\
\hline Öğün atlar mısını? & 37 & 30.6 \\
\hline Evet & 8 & 44.4 \\
Hayır & 12 & 2.8 \\
\hline Atlanılan öğün & 16 & 17.2 \\
\hline Kahvaltı & 1 & 8 \\
Öğlen & 12 & \\
Akşam & & \\
Ara öğün & & \\
\hline
\end{tabular}


Sporcuların ara ögünlerde tüketmiş oldukları suyu, \%51.1'inin kahve, \%22.2'sinin bisküvi, besinler incelendiğinde, \%26.7'sinin süt, \%9.1'inin cips, \%22.2'sinin kraker, \%61.4'ünün \%31.1'inin ayran, \%20'sinin kola, \%2'sinin gazoz, çikolata, \%27.3'ünün dondurma, \%22.2'sinin kek \%51.1'inin çay, \%64.4'ünün su, \%20'sinin meyve tükettiği görülmektedir (Tablo 3).

Tablo 3. Sporcuların ara öğünlerde tükettikleri besinler

\begin{tabular}{lcccc}
\hline Besinler & \multicolumn{2}{c}{ S } & \multicolumn{3}{c}{$\%$} \\
\hline Süt & Evet & Hayır & Evet & Hayır \\
Ayran & 12 & 33 & 26.7 & 73.3 \\
Kola & 14 & 31 & 31.1 & 68.9 \\
Gazoz & 9 & 36 & 20.0 & 80.0 \\
Çay & 1 & 44 & 2.2 & 97.8 \\
Su & 23 & 22 & 51.1 & 48.9 \\
Meyve suyu & 29 & 16 & 64.4 & 35.6 \\
Kahve & 9 & 36 & 20.0 & 80.0 \\
Bisküvi & 23 & 22 & 51.1 & 48.9 \\
Cips & 10 & 35 & 22.2 & 77.8 \\
Kraker & 4 & 40 & 9.1 & 90.9 \\
Çikolata & 10 & 35 & 22.2 & 77.8 \\
Dondurma & 27 & 17 & 61.4 & 38.6 \\
Kek & 12 & 32 & 27.3 & 72.7 \\
Diğer & 10 & 35 & 22.2 & 77.8 \\
\hline
\end{tabular}

Tablo 4'te sporcuların beslenme destek ürünleri kullanım durumları ve sıklıklarına bakıldığında, $\% 71.1$ 'inin besin destek ürünü kullanmadığı, \%28.9'unun ise besin destek ürünü kullandığ1 görülmektedir. Sporcular besin destek ürünü olarak amino asit, karbonhidrat barları, sporcu içeceği, kreatin, kafein, vitamin ve kilo aldırıcı tozlar kullandıklarını belirtmişlerdir. Kullanım sıklığ 1 ise bazen olarak belirtilmiştir. Besin destek ürünü kullanan sporcuların \%13.3'ünün antrenör, \%6.7'sinin arkadaş, \%4.4'ünün hekim, \%4.4'ünün ise diğer sağlık çalışanlarının önerileri doğrultusunda bu ürünleri tercih ettikleri ortaya çıkmıştır. Sporcuların \%11.1'i 1-3 ay, \%11.1'i 3-6 ay, \%6.7'si ise 6 ay ve daha uzun süre beslenme destek ürünü kullanmaktadır. Sporcuların \%84.6's1 kullandıkları beslenme destek ürünün yararını gördüklerini bildirirken, herhangi bir yan etki tanımlayan kişi olmamıştır. Sporcuların \%84.6's1 beslenme destek ürünleri için aylık 100-500 TL arasında giderlerinin olduğunu bildirmiştir. Genel olarak sporcuların \%30.8'i güçlü olmak, yine $\% 30.8$ 'i ise performanslarını arttırmak için besin destek ürünlerini kullanmaktadır. 
Tablo 4. Beslenme destek ürünleri kullanım durumları ve sıklıkları

\begin{tabular}{|c|c|c|c|}
\hline & & $\mathbf{S}$ & $\%$ \\
\hline \multicolumn{4}{|c|}{ Beslenme destek ürünü kullanıyor musunuz? } \\
\hline \multicolumn{2}{|l|}{ Evet } & 13 & 28.9 \\
\hline \multicolumn{2}{|l|}{ Hayır } & 32 & 71.1 \\
\hline \multicolumn{4}{|c|}{ Cevabınız evet ise kullanılan ürün } \\
\hline \multirow[t]{3}{*}{ Amino asit } & Düzenli & 3 & 23.1 \\
\hline & Bazen & 8 & 61.5 \\
\hline & Müsabaka dönemi & 2 & 15.4 \\
\hline \multirow[t]{3}{*}{ Karbonhidrat barları } & Düzenli & 1 & 7.7 \\
\hline & Bazen & 9 & 69.3 \\
\hline & Müsabaka dönemi & 3 & 23.2 \\
\hline \multirow[t]{2}{*}{ Sporcu içecekleri } & Bazen & 12 & 92.4 \\
\hline & Müsabaka dönemi & 1 & 7.7 \\
\hline \multirow[t]{3}{*}{ Kreatin } & Düzenli & 5 & 38.5 \\
\hline & Bazen & 7 & 53.9 \\
\hline & Müsabaka dönemi & 1 & 7.7 \\
\hline \multirow[t]{2}{*}{ Kafein } & Düzenli & 3 & 23.1 \\
\hline & Bazen & 10 & 76.9 \\
\hline \multirow[t]{3}{*}{ Vitamin } & Düzenli & 3 & 23.1 \\
\hline & Bazen & 9 & 69.3 \\
\hline & Müsabaka dönemi & 1 & 7.7 \\
\hline \multirow[t]{3}{*}{ Kilo aldıran tozlar } & Düzenli & 2 & 15.4 \\
\hline & Bazen & 10 & 76.9 \\
\hline & Müsabaka dönemi & 1 & 7.7 \\
\hline \multicolumn{4}{|l|}{ Kim önerdi? } \\
\hline \multicolumn{2}{|l|}{ Arkadaş } & 3 & 6.7 \\
\hline \multicolumn{2}{|l|}{ Antrenör } & 6 & 13.3 \\
\hline \multicolumn{2}{|l|}{ Hekim } & 2 & 4.4 \\
\hline \multicolumn{2}{|l|}{ Sağlık çalışanları } & 2 & 4.4 \\
\hline \multicolumn{4}{|c|}{ Ne kadar süredir kullanıyorsunuz? } \\
\hline \multicolumn{2}{|l|}{$1-3$ ay aras1 } & 5 & 11.1 \\
\hline \multicolumn{2}{|l|}{ 3-6 ay aras1 } & 5 & 11.1 \\
\hline \multicolumn{2}{|l|}{6 ay ve daha fazla } & 3 & 6.7 \\
\hline \multicolumn{4}{|l|}{ Yararını gördünüz mü? } \\
\hline \multicolumn{2}{|l|}{ Evet } & 11 & 84.6 \\
\hline \multicolumn{2}{|l|}{ Hayır } & 2 & 15.4 \\
\hline \multicolumn{4}{|l|}{ Zararını gördünüz mü? } \\
\hline \multicolumn{2}{|l|}{ Evet } & - & - \\
\hline \multicolumn{2}{|l|}{ Hayır } & 13 & 100.0 \\
\hline Bir ayda ürünler için & ne kadar para harc & & \\
\hline$\leq 100 \mathrm{TL}$ & & 2 & 15.4 \\
\hline $100-500 \mathrm{TL}$ & & 11 & 84.6 \\
\hline
\end{tabular}


Tablo 4. Beslenme destek ürünleri kullanım durumları ve sıklıkları

\begin{tabular}{lcc}
\hline Bu ürünleri kullanmaya neden gerek duydunuz? & & \\
\hline Güçlü olmak & 4 & 30.8 \\
Kas oranını arttırmak & 1 & 7.7 \\
Yetersiz beslendiğim için & 2 & 15.4 \\
Performans arttırmak & 4 & 30.8 \\
Kilo vermek & 2 & 15.4 \\
\hline
\end{tabular}

\section{Tartışma}

Dengeli beslenme genç sporcuların sadece fiziksel gelişmelerini değil, antrenman ve yarışlardaki sonuçlarını da etkilemektedir. Sporcular için, beslenmenin temel amacı artmış enerji ihtiyacını ve besin öğesi gereksinmelerini karşılayarak fiziksel yüklenmeye adaptasyonu maksimize edebilmektir (10). Bu nedenle sporcuların beslenme alışkanlıkları, performansları açısından oldukça önemlidir. Çalışmamız, İstanbul Aydın Üniversitesi'nde eğitim gören çeşitli branşlardaki sporcuların beslenme alışkanlıkları ve besin takviyesi kullanımlarının belirlenmesi amacıyla yürütülmüştür ve çalışmaya 23 erkek, 22 kadın olmak üzere toplam 45 sporcu katılmıştır.

Sporda beslenmenin önemi, çalışma verimi ile beslenme arasındaki ilişkiyi araştıran çok sayıda çalışma ile belirlenmiştir. Sporcuların yeterli ve dengeli beslenmesi özellikle performans sporcularında daha da önemlidir (11). Enerji gereksiniminin karşılanması performans için son derece önemli olup enerji alımı, antrenman, antrenmanın türü ve maç saatine göre ayarlanmalıdır. Yüksek enerji gereksinimi sporcuların beslenmesinde ana ve ara öğünlere dağıtılarak karşılanmalıdır, bu noktada sporcularda ana ve ara öğün sayısı oldukça önemlidir. Yarar ve ark. yapmış olduğu çalışmada, sporcuların \%56.9'unun üç öğün, \%37.1'inin dört öğün ve üstü, \%6'sının ise iki ögün yemek yemediği saptanmıştır (12). Bir başka çalışmada ise sporcuların ana ve ara öğünlerine ilişkin tutumlarına bakıldığında, \%91.1'inin öğün atlamadan sabah, öğle ve akşam yemeği yediği, \%67.6'sının ara öğün tükettiği belirlenmiştir (13). Profesyonel basketbolcular üzerinde yapılan bir araştırmada ise $\% 8.5$ 'inin 2 öğün, \%53.2'sinin 3 öğün, \%38.3'ünün 4 öğün ve üzeri olarak öğün tükettikleri saptanmıştır. En fazla atlanılan öğün \%53.1 ile kahvaltı, sonra \%40.6 ile öğle ve \%6.3 ile akşam öğünleri olduğu bulunmuştur (14). Duman'nın çalışmasında da yüzücülerde kahvaltı öğününü atlayanların oranı $\% 16$, öğle yemeğini atlayanların oranı \%6.6 ara öğünlerin atlanma oranı ise \%77.4 olarak belirlenmiştir (15). Çalışmamızda sporcuların beslenme alışkanlıkları incelendiğinde \%55.6'sının günde 3 ana öğün, \%44.4'ünün günde 2 ara öğün yaptığ1 görülmektedir. Sporcuların \%82.2'si öğün atlarken, \%44.4'ünün öğlen, \%30.6'sinın ise kahvaltı ögününü atladığı tespit edilmiştir (Tablo 2). Günde 3 öğün yapanların oranı genel olarak ülkemizde yapılan çalışmalarla uyum içerisindedir. Ancak 2 öğün yapanların oranının yüksek olması (\%35.6) yetersiz enerji alımı açısından bir risk olarak değerlendirilmiştir. Sporcuların en az 1 ara öğün yapıyor olmaları da olumlu bir beslenme alışkanlığı olarak yorumlanmıştır.

Sporcuların ara öğünlerde tüketmiş oldukları yiyecekler sorgulandığında \%26.7'sinin süt, $\% 31.1$ 'inin ayran, \%20'sinin kola, \%2'sinin gazoz, $\% 51.1$ 'inin çay, \%64.4'ünün su, \%20'sinin meyve suyu, \%51.1'inin kahve, \%22.2'sinin bisküvi, $\% 9.1$ 'inin cips, \%22.2'sinin kraker, \%61.4'ünün çikolata, \%27.3'ünün dondurma, \%22.2'sinin kek tükettiği görülmektedir (Tablo 3). Değişik spor dallarındaki sporcuların beslenme alışkanlıklarının sorgulandığı çalışmalarda, ara öğünlerde tükettikleri besinler şu şekilde sıralanmıştır; meyve (\%27), kuruyemiş (\%22.5), neskafe (\%22.5), simit/ poğaça $(\% 2.7)$, sandviç $(\% 2.7)$ ve tatlı $(\% 2.7)$ (13), sporcuların \%26.8'inin meyve suyu ve gazlı içecekleri, \%44.7'sinin kuruyemişleri, \%15.8'inin ise meyveyi daha çok tükettikleri bulunmuştur (14). Profesyonel futbolcuların \%60.8'i meyveyi, 
\%26.3'ü çikolatay1, \%7.9'u tostu ve \%5'i bisküviyi, amatör futbolcuların \%49.2'si meyveyi, $\% 32.5$ 'i çikolatayı, \%6.7'si tostu ve \%11.7'si bisküviyi öğün dışı daha çok tüketmektedirler (16). Literatürdeki ara öğün tercihlerine benzer şekilde tercihler görülmekle birlikte kahve çikolata tüketiminin çok daha fazla olduğu ancak meyve ve kuruyemiş tercihinin ise olmadığı görülmektedir. Tercihlerin sporcu beslenmesi için sağlıklı ve doğru olmadığı bu nedenle de sporculara verilen eğitimin sıklaştırılması gerektiği şeklinde yorumlanmıştır. Bununla birlikte son y1llarda sporcu içeceği olarak anılmaya başlanan süt ve ayranın sporcular tarafından ara öğün olarak tercih ediliyor olması olumlu olarak yorumlanmıştır.

Sporcuların \%40-100’ü besin takviyesi kullanmaktadır. Sporcunun besin öğesi yetersizliği olmadığı sürece, takviyeler performans1 iyileştirmemektedir ve aksine sağlık ve performans üzerine olumsuz etkiler de yapabilmektedir (17). Yapılan bir çalışmada sporcuların \%97.2'si spor kariyerlerinin bir döneminde besin takviyesi kullandığını belirtmişlerdir (18). Literatürde sporcuların besin takviyesi kullanımı oldukça araştırılmış olup \%48.2 (19), \% 55.7 (12) ve \%55'den (20), \%40-100'a kadar (17) değişik oranlar bildirilmektedir.

Profesyonel sporcuların arasında en popüler besin destek ürünleri; protein, sporcu içecekleri, multi vitaminler ve karbonhidrat takviyeleri olarak belirlenmiştir (21). Kanadalı genç sporcular arasında ise sporcu içecekleri, enerji içecekleri, vitaminle zenginleştirilmiş sular, vitamin veya mineraller tek başına ya da sporcu barları, protein tozları, karnitin yağ asit preparatları ya da bitkisel ekstraktlarla kombinasyon olarak tüketildiği saptanmıştır (1). Protein bazlı sporcu takviyeleri sporcular arasinda en sik tercih edilen besin takviyelerden olup Avustralya'da 13-18 yaşlarında 87 sporcu üzerinde yapılan çalışmada sporcuların \%60'ının protein takviyesi kullandığı ve kullanımın yaş ile ilişki olduğu bulunmuştur.

Katılımcıların \%55'i protein takviyesi kullanımının riskle ilişkili olduğunun farkında olduğunu belirtirken, en sik bildirilen risk cevabı \%22 ile bilmiyorum şeklinde olduğu bildirilmiştir (22). Mevcut çalışmada sporcuların beslenme destek ürünleri kullanım durumları ve sıklıklarına bakıldığında, \%71.1'inin beslenme destek ürünü kullanmadığı, \%28.9'unun ise besin destek ürünü kullandığı görülmektedir. Çalışmamızda sporcuların besin destek kullanım oranı literatürden daha düşük olarak bulunmuştur. Kullanılan besin destek ürünleri açısından incelendiğinde ise sporcuların literatürle benzer şekilde en fazla aminoasit, karbonhidrat barları, sporcu içeceği, kreatin, kafein, vitamin ve kilo aldırıcı tozları kullandıkları belirlenmiştir.

Besin destek ürünü kullanımına yönlendiren kaynakların sorgulandığı bir çalışmada, sporcular diyetisyenleri en güvenilir bilgi kaynağ1 gösterirken (21), çoğu çalışmada sporcular bilgi kaynağı olarak koçlarını (22) ve kondisyonerlerini göstermektedir $(10,23)$.

Sporcuların besin destek ürünleri kullanma nedenleri arasında en sik belirtilenler, egzersiz sonrası toparlanmayı destekleme, immun sistemi destekleme ve enerji sağlama olarak bulunmuştur (21). Çalışmamızda da benzer olarak ürün kullanım önerisi \%13.3 oranı ile en fazla antrenör tarafından yapılmaktadır ve sporcuların \%84.6'sı kullandıkları beslenme destek ürününün yararını gördüklerini bildirirken, herhangi bir yan etki tanımlayan olmamıştır. Genel olarak sporcuların \%30.8'inin güçlü olmak, \%30.8'inin ise performanslarını arttırmak için besin destek ürünlerinin kullandığ saptanmıştır.

Sonuç olarak, neredeyse tüm sporcular spor kariyerlerinin bir döneminde besin destek ürünü kullanmaktadır ve takviye kullanımı genellikle antrenör tarafindan şekillendirilmektedir. Genel olarak, sporcularda eksikliği bulunan ya da dengeli bir diyetle karşılanmayan gereksinmelerden ziyade popüler ürünlerin tercih edildiği görülmüştür. Performans için beslenmenin önemi büyüktür ancak destek ürün kullanımı kim için ve ne kadar sorularını da içinde barındıran oldukça tartışmalı bir konudur. Bazen kontaminantlar nedeniyle sporcuların müsabakalarda diskalifiye edilmesine kadar gidebilen sonuçlar doğurabilmektedir. $\mathrm{Bu}$ 
nedenle özellikle genç sporcularda beslenme eğitimi arttırılarak performans artışına gidilmeli ve eğer gerekiyorsa besin takviyesi kullanımı sağlık profesyonelleri denetimde yapılmalıdır.

\section{KAYNAKLAR}

1. Parnell JA, Wiens K, Erdman KA. Evaluation of congruence among dietary supplement use and motivation for supplementation in young, Canadian athletes. Journal of the International Society of Sports Nutrition 2015; 12:49.

2. Tawfik S, Koofy NE, Moawad EMI. Patterns of nutrition and dietary supplements use in young Egyptian athletes: A community-based crosssectional survey. Plos One 2016; 11(8): e0161252.

3. Salgado JVV, Lollo PCB, Farfan JA et al. Dietary supplement usage and motivation in Brazilian road runners. Journal of the International Society of Sports Nutrition 2014; 11:41.

4. Aljaloud SO, İbrahim SA. Use of dietary supplements among professional athletes in Saudi Arabia. Journal of Nutrition and Metabolism 2013; 1-7.

5. Dascombe BJ, Karunaratna M, Cartoon J et al. Nutritional supplementation habits and perceptions of elite athletes within a state-based sporting institute. J Sci Med Sport 2010; 13(2):274-80.

6. Knapik JJ, Steelman RA, Hoedebecke SS et al. Prevalence of dietary supplement use by athletes: Systematic review and meta-analysis. Sports Medicine 2016; 46(1):103-123.

7. Solheim SA, Nordsborg NB, Ritz C et al. Use of nutritional supplements by Danish elite athletes and fitness customers. Scand J Med Sci Sports 2017; 27(8):801-808.

8. Sato A, Kamei A, Kamihigashi E et al. Use of supplements by Japanese elite athletes for the 2012 olympic games in London. Clinical Journal of Sport Medicine 2015; 25(3):260-269.

9. Lieberman HR, Marriott BP, Williams $\mathrm{C}$ et al. Patterns of dietary supplement use among college students. Clinical Nutrition 2015; 34(5):976-85.
10. Hull MV, Jagim AR, Oliver JM et al. Gender differences and access to a sports dietitian influence dietary habits of collegiate athletes. Journal of the International Society of Sports Nutrition 2016; 13:38.

11. Argan M, Köse H. Sporcu Besin Desteklerine (Sports Supplements) Yönelik Tutum Faktörleri: Fitness Merkezi Katılımc1ları Üzerine Bir Araştırma. Hacettepe J. of Sport Sciences 2009; 20(4):152-164.

12. Yarar H, Gökdemir K, Eroğlu $H$ et al. Elit Seviyedeki Sporcuların Beslenme Bilgi Ve Alışkanlıklarının Değerlendirilmesi. Selçuk Üniversitesi Beden Eğitimi ve Spor Bilim Dergisi 2011;13(3):368-371.

13. Özdoğan Y, Karataş E, Uçar A. Vücut Geliştirme Sporu Yapan Erkeklerin Beslenme Alışkanlıkları Ve Ergojenik Besin Destekleri Kullanma Durumları. ACU Sağlık Bil Derg 2018; 9(4):378-384.

14. İnce B. Profesyonel Basketbolcularda Beslenme Alışkanlıkları Ve Bilgi Düzeylerinin İncelenmesi (Uzmanlık Tezi). İstanbul, Haliç Üniversitesi, 2017.

15. Duman EU. 10-18 Yaş Grubu Yüzücülerin Beslenme Bilgi Düzeyleri İle Bazı Parametrelerin İlişkisinin Saptanması (Uzmanlık Tezi). İstanbul, Haliç Üniversitesi, 2011.

16. Saygın Ö, Göral K, Gelen E. Amatör ve Profesyonel Futbolcularin Beslenme Alışkanlıklarının İncelenmesi. Uluslararası İnsan Bilimleri Dergisi 2009; 6(2).

17. Garthe I, Maughan RJ. Athletes and supplements: Prevalence and perspectives. International Journal of Sport Nutrition and Exercise Metabolism 2018; 28(2):126-138.

18. Wardenaar FC, Ceelen IJ, Van Dijk JW et al. Nutritional supplement use by Dutch elite and subelite athletes: Does receiving dietary counseling make a difference? International Journal of Sport Nutrition and Exercise Metabolism 2017; 27(1):3242. 
19. Frączek B, Warzecha M, Tyrała $F$ et al. Prevalence of the use of effective ergogenic aids among professional athletes. Rocz Panstw Zakl Hig $2016 ; 67(3): 271-278$.

20. Colls Garrido C, Gómez-Urquiza JL, CañadasDe la Fuente GA et al. Use, effects, and knowledge of the nutritional supplements for the sport in university students. Nutricion Hospitalaria 2015; 32(2):837-844.

21. Graham-Paulson TS, Perret C, Smith B et al. Nutritional supplement habits of athletes with an impairment and their sources of information. International Journal of Sport Nutrition and Exercise Metabolism 2015; 25(4):387-95.
22. Whitehouse G, Lawlis T. Protein supplements and adolescent athletes: A pilot study investigating the risk knowledge, motivations and prevalence of use. Nutr Diet 2017; 74(5):509-515.

23. Denham BE. Athlete information sources about dietary supplements: A review of extant research. International Journal of Sport Nutrition and Exercise Metabolism 2017; 27(4):325-334. 